\title{
A review: microstructure and properties of tin-silver- copper lead-free solder series for the applications of electronics
}

\author{
Muhammad Aamir \\ School of Engineering, Edith Cowan University, Joondalup, Australia \\ Riaz Muhammad \\ Department of Mechanical Engineering, University of Bahrain, Sakheer, Bahrain \\ Majid Tolouei-Rad \\ School of Engineering, Edith Cowan University, Joondalup, Australia \\ Khaled Giasin \\ School of Mechanical and Design Engineering, University of Portsmouth, Portsmouth, UK, and \\ Vadim V. Silberschmidt \\ Wolfson School of Mechanical, Electrical and Manufacturing Engineering, Loughborough \\ University, Loughborough, UK
}

\begin{abstract}
Purpose - The research on lead-free solder alloys has increased in past decades due to awareness of the environmental impact of lead contents in soldering alloys. This has led to the introduction and development of different grades of lead-free solder alloys in the global market. Tin-silvercopper is a lead-free alloy which has been acknowledged by different consortia as a good alternative to conventional tin-lead alloy. The purpose of this paper is to provide comprehensive knowledge about the tin-silver-copper series.

Design/methodology/approach - The approach of this study reviews the microstructure and some other properties of tin-silver-copper series after the addition of indium, titanium, iron, zinc, zirconium, bismuth, nickel, antimony, gallium, aluminium, cerium, lanthanum, yttrium, erbium, praseodymium, neodymium, ytterbium, nanoparticles of nickel, cobalt, silicon carbide, aluminium oxide, zinc oxide, titanium dioxide, cerium oxide, zirconium oxide and titanium diboride, as well as carbon nanotubes, nickel-coated carbon nanotubes, single-walled carbon nanotubes and graphene-nano-sheets.

Findings - The current paper presents a comprehensive review of the tin-silver-copper solder series with possible solutions for improving their microstructure, melting point, mechanical properties and wettability through the addition of different elements/nanoparticles and other materials. Originality/value - This paper summarises the useful findings of the tin-silver-copper series comprehensively. This information will assist in future work for the design and development of novel lead-free solder alloys.
\end{abstract}

Keywords Wettability, Alloying element, Mechanical properties, Melting point, Microstructure, Tin-silver-copper series

Paper type Research paper

\section{Introduction}

Soldering is the joining of two or more metals by means of a third metal, or alloy, with a relatively lower melting point (MP) (Efzan and Marini, 2012). Solder joints are used to physically hold assemblies together, allowing contraction and expansion of different components, dissipating any generated heat and transmitting electrical signals. Therefore, the reliability of a solder joint depends on the performance and quality of the solder alloy (Aamir et al., 2015). In the early era of the microelectronics industry, tin-lead $\left(S_{63}-P_{37}\right)$ was most commonly used (Ma and Suhling, 2009). This was due to the combined merit of low cost and good mechanical, metallurgical and physical properties, mainly facilitated by the lead $(\mathrm{Pb})$ (Lee, 1997). However, lead's use in electronics is now restricted by legislation worldwide due to environmental concerns (Cheng et al., 2017). Therefore, electronics manufacturers require a reliable lead-free solder (LFS) that is environmentally benign (Lee, 1997).

The most popular LFS alloys are in the tin-silver-copper (SAC) series (Aamir et al., 2017a; Aamir et al., 2017b). A survey has shown that almost 70 per cent of accepted lead-free solders (LFSs) are $S A C$ alloys, due to their comparatively good properties (Shnawah et al., 2012). In addition, the $S A C$ series provides better mechanical support in electronic devices because of its good joint strength (Harrison et al., 2001). In 
$S A C$, the near eutectic composition consists of a high volume of a $\beta$-tin ( $S n$ ) matrix and intermetallic compounds, (IMCs) namely $\mathrm{Ag}_{3} \mathrm{Sn}, \mathrm{Cu}_{6} \mathrm{Sn}_{5}$ and $\mathrm{Cu}_{3} \mathrm{Sn}$ (El-Daly et al., 2013). In comparison to the $S n$-matrix, the IMCs are brittle in nature (Sadiq et al., 2013). It is worth noting that the formation of $\mathrm{Ag}_{3} \mathrm{Sn}$ is due to the reaction between $\mathrm{Sn}$ and Silver $(\mathrm{Ag})$, whereas $\mathrm{Cu}_{6} \mathrm{Sn}_{5}$ is possibly formed by the reaction between $S n$ and copper ( $\mathrm{Cu}$ ). No reaction has been found between $\mathrm{Ag}$ and $C u$ for the formation of any types of IMCs (Vianco and Shangguan, 2006). It has also been reported that $C u_{3} S n$ does not form at the eutectic point unless the content of $\mathrm{Cu}$ is high enough for its formation at high temperature (Ma and Suhling, 2009). $C u$ additions in the $S A C$ series improve their wettability and lower their melting temperature (Nimmo, 2004). Furthermore, higher $A g$ contents in the $S n$-rich matrix yield a higher amount of $\mathrm{Ag}_{3} \mathrm{Sn}$, which may result in higher strength. However, high $\mathrm{Ag}$ contents with high elastic moduli $(E)$ and yield strengths (YS) show reasonably low ductility (Che et al., 2010).

Unfortunately, $S A C$ solders still exhibit some problems such as higher $M P$, poor wettability and coarser microstructures (Sadiq et al., 2013). To overcome these problems, and to further improve the reliability of solder joints, different elements and/or micro or nanoparticles have been added to change the microstructure and enhance other properties (Sona and Prabhu, 2013). In this review, the impact of adding different elements/nanoparticles and other materials on the $M P$, microstructure, mechanical properties and wettability of all $S A C$ family members is presented.

\section{Melting point}

Melting temperature (MT) is one of the most important properties for the development of LFSs (El-Daly and Hammad, 2012). $M T$ is the liquidus temperature $\left(T_{L}\right)$ making the solder alloy completely molten, which is necessary for soldering operations (Abtew and Selvaduray, 2000). The $M T$ is essential to develop better solder joints and occurs if the solidus temperature $\left(T_{S}\right)$ is low (Mei et al., 1996) because rapid solidification can provide a better and more refined microstructure which has a direct impact on a solder joint's strength (Kanlayasiri et al., 2009). Moreover, a good solder alloy should have a narrow melting range $\left(\Delta T=T_{L}-T_{S}\right)$ and low $M T$ (El-Daly and Hammad, 2012). Taking into account that a conventional eutectic $\mathrm{Sn}-\mathrm{Pb}$ solder melts at $183^{\circ} \mathrm{C}$, this can be considered as the benchmark for new LFSs (Jeon et al., 2008). However, the $M P$ of $S A C$ is approximately $217^{\circ} \mathrm{C}$, which results in thicker IMCs than those of $S n-P b$. Therefore, some researchers have added alloying elements, or nanoparticles, to reduce the $M T$ of the $S A C$ series. For instance, Kanlayasiri et al. (2009) reported that the doping of indium (In) into $S A C$ lowers the $T_{S}$ and $T_{L}$. Their results concluded that, upon addition of $3 \mathrm{Wt}$. \% In to $S A C, T_{S}$ $\left(219.4^{\circ} \mathrm{C}\right)$ and $T_{L}\left(241.7^{\circ} \mathrm{C}\right)$ decreased by $21.7^{\circ} \mathrm{C}$ and $11.5^{\circ} \mathrm{C}$, respectively. Subsequently, the difference between $T_{S}$ and $T_{L}$ of the $S A C$ increased from $22.3^{\circ} \mathrm{C}$ to $32.5^{\circ} \mathrm{C}$. However, In is expensive and it increases the cost of LFSs. Chuang et al. (2012) investigated the influence of titanium (Ti) on the $M T$ of $S A C$. Their results showed that the addition of $1.0 \mathrm{Wt} . \%$ of $T i$ into $S A C$ decreased the $T_{S}$ and $T_{L}$ from $216.92^{\circ} \mathrm{C}$ and $221.58^{\circ} \mathrm{C}$ to $216.59^{\circ} \mathrm{C}$ and $219.47^{\circ} \mathrm{C}$, respectively. In addition, the melting range of $S A C$ also decreased from $4.66^{\circ} \mathrm{C}$ to $2.88^{\circ} \mathrm{C}$. A narrow melting range is one of the desirable thermal properties of solders, meaning they exist in the liquid form only for a very short time during solidification for the formation of acceptable joints. In another study by Shnawah et al. (2013), differential scale calorimetry (DSC) analysis was used to check the thermal behaviour of $S A C$ after the addition of iron $(\mathrm{Fe})$. They found that $0.6 \mathrm{Wt}$. \% of $\mathrm{Fe}$ gave a lower $M P$ by showing one endothermic peak at $221.35^{\circ} \mathrm{C}$ at a eutectic composition. Huang and Wang (2005) also reported a decrease in the $M P$ of $S A C$ upon addition of bismuth (Bi). According to their findings, the $T_{S}$ of $S A C-2 B i$ and $S A C-4 B i$ were $213.08^{\circ} \mathrm{C}$ and $206.40^{\circ} \mathrm{C}$, respectively. However, peeling of the solder joint appeared when the $B i$ addition was $>4 \mathrm{Wt} . \%$.

Furthermore, the addition of Rare-Earth (RE) elements (Wu and Wong, 2007) and nanoparticles (Efzan Mhd Noor et al., 2013) have also contributed better properties to SAC, while not drastically affecting the $M P$. For instance, Dudek and Chawla (2010) studied the DSC curves of $S A C$ and $S A C$ $0.5 R E$. Their selected $R E$ elements were lanthanum $(L a)$, cerium $(\mathrm{Ce})$, and yttrium $(Y)$, where it was found that all solders ( $\mathrm{La}, \mathrm{Ce}$, and $\mathrm{Y}$ ) displayed a single endothermic peak between $217^{\circ} \mathrm{C}$ and $219^{\circ} \mathrm{C}$. Liu et al. (2008) studied the minor addition of silicon carbide $(\mathrm{SiC})$ nanoparticles to the $S A C$ and found that it did not change its $M T$ noticeably. However, upon the addition of only $0.2 \mathrm{Wt} . \% \mathrm{SiC}$, a lower $M P$ value was observed as the endothermic peak shifted from $219.9^{\circ} \mathrm{C}$ to $218.9^{\circ} \mathrm{C}$. Tsao et al. (2013) analysed $D S C$ curves of $S A C$ doped with aluminium oxide $\left(\mathrm{Al}_{2} \mathrm{O}_{3}\right)$ nanoparticles. It was found that the $M P$ of $S A C$, which was $221.2^{\circ} \mathrm{C}$, slightly increased as the amount of $\mathrm{Al}_{2} \mathrm{O}_{3}$ nanoparticles increased. Gain et al. (2011) also observed no significant change in the $M P$ of $S A C$ with $1 \mathrm{Wt}$. $\%$ of titanium dioxide $\left(\mathrm{TiO}_{2}\right)$ nanoparticles. It was concluded that DSC analyses gave only a eutectic peak from $217.00^{\circ} \mathrm{C}$ to $217.64^{\circ} \mathrm{C}$. Similar behaviour was noted in another study by Chang et al. (2011). In conclusion, adding alloying elements and nanoparticles to $S A C$ alloys had little effect on the $M T$.

\section{Microstructure}

A thin layer of IMCs is required to attain a better metallurgical bond for the reliability of electronic solders; however, their higher growth has undesirable impacts on the mechanical properties due to their brittle nature (Liang et al., 2014). Therefore, it is important to expand the knowledge of IMCs for the reliability of solder interconnections (Aamir et al., 2017c; Aamir et al., 2019). In this review, the addition of alloying elements etc into $S A C$ alloys is discussed to highlight the impact of precipitates in suppressing the growth of IMCs for refined and uniform microstructures.

Chuang et al. (2012) concluded that, after the addition of different amounts of $T i$ into $S A C$, the microstructure became uniform due to the active properties of $T i$, which gave rise to heterogeneous IMCs and reduced the dendritic size. However, it was recommended that the $T i$ concentration should not exceed $1.0 \mathrm{Wt} . \%$, which in turn gave rise to coarse $\mathrm{Ti}_{2} \mathrm{Sn}_{3}$ in the eutectic colonies and made the microstructure worse. Sabri et al. (2013) found that inclusions of aluminium $(A l)$ in 
$S A C$ led to the arrangement of a large amount of additional $\mathrm{Ag}_{3} \mathrm{Al}$ and $\mathrm{Al}_{2} \mathrm{Cu}$ IMCs. These IMCs possessed snowflake, circle, rod, and quadrangle shaped morphologies and were lightly distributed within the microstructures located in and at the vicinity of interdendritic regions. Moreover, these additional IMCs refined the microstructure of $S A C$ by restraining the growth formation of IMCs $\left(\mathrm{Ag}_{3} \mathrm{Sn}\right.$ and $\left.\mathrm{Cu}_{6} S n_{5}\right)$. In another study by Leong and Haseeb (2016), the effect of a minor addition of $A l$ into $S A C$ on the interfacial structure between the solder and copper substrate during reflow was investigated. It was determined that the minor addition of $A l$ into $S A C$ formed small equiaxed $\mathrm{Cu}-\mathrm{Al}$ particles, $\mathrm{Cu}_{3} \mathrm{Al}_{2}$, which suppressed the growth of the interfacial $\mathrm{Cu}_{6} S n_{5} I M C$ after reflow. Zhang et al. (2012a) investigated doping of zinc $(Z n)$ into $S A C$, which remarkably refined the microstructure with the condition that concentrations of $Z n$ should be limited to $0.8 \mathrm{Wt}$.\%. The refinement in microstructure was due to the formation of dispersed $C u-Z n$ IMCs which reduced the thickness of the IMCs and ultimately changed the morphology. Hammad (2013) found that adding $0.05 \mathrm{Wt} \% \mathrm{Ni}$ into $S A C$ formed $(\mathrm{Cu}, \mathrm{Ni})_{6} \mathrm{Sn}_{5}$ IMCs in the eutectic regions, which decreased the inter-particle spacing and resulted in a more refined morphology. Wang et al. (2019) fabricated SAC with $0.2 \mathrm{Wt}$ \% zirconium $(\mathrm{Zr})$ using a vacuum induction melting method. Their study demonstrated that $Z r$ refined the microstructure of $S A C$ by reducing the size of the IMCs, which further participated in improving the strength of the solder alloy. Moreover, $0.2 \mathrm{Zr}$ Wt.\% gave significantly better results, even after isothermal aging. However, no change in the melting range was observed.

$R E$ elements are good surface-active agents and are considered vital materials for improving the microstructure and mechanical properties (Sadiq et al., 2013). They can accumulate at grain/dendrite boundaries and can lower the energy of the grain/dendrite boundary by restricting the motion of the boundaries. Thus, they restrict the growth of IMCs and give a refined microstructure (Xia et al., 2002). Dudek and Chawla (2010) reported that $R E$ addition into $S A C$ produced $R E$-containing particles, i.e. $R E S n_{3} I M C$, apart from $\mathrm{Cu}_{6} S n_{5}$ and $\mathrm{Ag}_{3} \mathrm{Sn}$, which were responsible for the refinement of the microstructure as shown in Figure 1.

In addition, Yasmin and Sadiq (2014) concluded that the appropriate composition of $L a$ in $S A C$ reduced the grain size and provided better microstructure by effectively suppressing the growth rate of IMCs $\left(\mathrm{Ag}_{3} \mathrm{Sn}\right.$ and $\left.\mathrm{Cu}_{6} S n_{5}\right)$ even during thermal ageing. This refinement in the $S A C$ microstructure was due to the aggregation of $L a$ at the interface, which provided blockage for the production of large IMCs. The same recommendation was made in another study by Sadiq et al. (2013). Moreover, a careful examination of the microstructure after $C e$ inclusion in $S A C$ was done by W Chen et al. (2011). Their results showed that adding $C e$ promoted the formation of $C e-S n I M C s$ which acted as a blockage to decrease the growth of $\mathrm{Ag}_{3} \mathrm{Sn}$ and $\mathrm{Cu}_{6} \mathrm{Sn}$; thus, giving a refined microstructure. Zhang et al. (2012b) also studied the contribution of $0.03 \mathrm{Wt} \% \mathrm{Ce}$ in $S A C$. Their study showed that the activation energy for the growth of IMCs was higher for $C e$-based $S A C$, which was responsible for reducing the growth of IMCs and increasing the strength of the solder joint. Furthermore, Tu et al. (2017) reported that $0.15 \mathrm{Wt} \%$ of $C e$ in $S A C$ improved the
Figure 1 SEM micrographs of (a) SAC with the addition of $0.5 \mathrm{Wt}$. \% of (b) La, (c) Ce and (d) $Y$
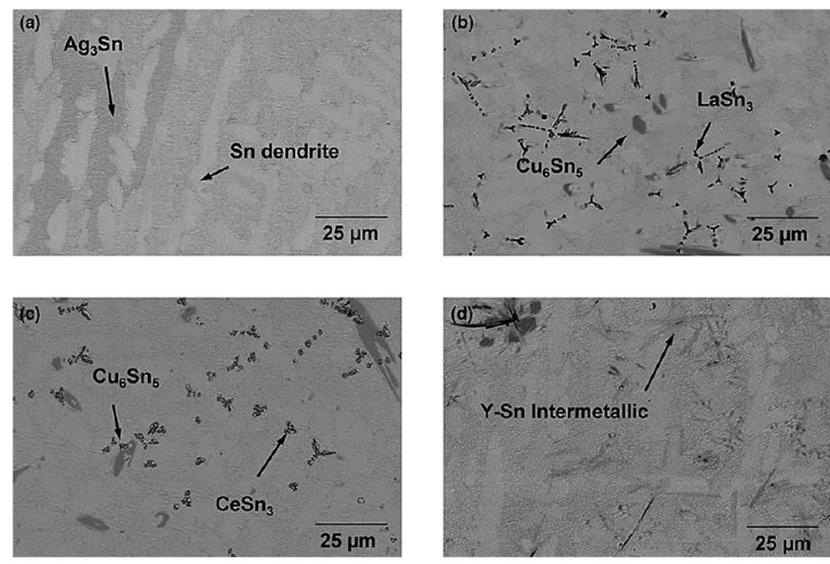

Source: Dudek and Chawla (2010)

microstructure by reducing the thickness of the IMCs. Zhang et al. (2014) reported that additions of $0.05 \mathrm{Wt} . \%$ of ytterbium $(Y b)$ in $S A C$ improved the properties for electronic packaging and refined the microstructure by retarding the growth of IMCs during soldering. In another study (Gao et al., 2010b), the incorporation of a small concentration of praseodymium ( $\mathrm{Pr}$ ) in $S A C$ was shown to produce extra $\mathrm{PrSn}$ particles which restricted the IMC growth because of the heterogeneous nucleation by lowering the reaction time of the liquid solder with the substrate. However, more than $0.05 \mathrm{Wt} . \%$ of $\mathrm{Pr}$ resulted in the arrangement of the bulk $\mathrm{PrSn}{ }_{3}$ compound.

Nanoparticles also play a vital role in changing the microstructure of SAC alloys. For instance, Liu et al. (2008) concluded that the inclusion of $0.05 \mathrm{Wt} . \% \mathrm{SiC}$ nanoparticles remarkably decreased the average grain size, due to the strong adsorption effect and high surface free energy, which led to refined IMCs. Sharma et al. (2019) used a simple mechanical blending and casting method to add zirconia $\left(\mathrm{ZrO}_{2}\right)$ nanoparticles to $S A C$. It was concluded that, after the addition of $\mathrm{ZrO}_{2}$ nanoparticles, the thickness of the grain size, and IMCs such as $\mathrm{Ag}_{3} \mathrm{Sn}$ and $\mathrm{Cu}_{6} \mathrm{Sn}_{5}$ were refined by 46 per cent, 14 per cent, and 26 per cent, respectively compared to the original $S A C$ alloy. Bashir et al. (2016) used a nanoparticle-doped flux technique to add $2 \mathrm{Wt}$. $\%$ Co nanoparticles into $S A C$. The influence of the Co nanoparticle-doped flux was then investigated with an electro-migration (EM) test performed in an oil bath at $80^{\circ} \mathrm{C}$ for a duration of $1128 \mathrm{~h}$ with a current density of $1 \times 10^{4} \mathrm{~A} / \mathrm{cm}^{2}$. Their study concluded that the presence of $2 \mathrm{Wt}$ \% Co nanoparticles in $S A C$ restricted the size of the IMCs, both at the cathode and anode sides. In addition, the tensile strength of the solder joint increased after the addition of $C o$ nanoparticles when the $E M$ test was performed at $150^{\circ} \mathrm{C}$ for $0 \mathrm{~h}$ and $192 \mathrm{~h}$. This study showed that a $2 \mathrm{Wt} . \%$ Co nanoparticle-doped flux improved the reliability of $S A C$ solder joints. Sujan et al. (2017) also worked on the addition of Co nanoparticles using the flux doping technique. This method is useful with surface mount technology and does not require any further steps in the manufacturing line. Their results showed that the addition of $\mathrm{Co}$-nanoparticles with an average 
size of $58 \mathrm{~nm}$ into $S A C$ stabilised the formation of $C u_{6} S n_{5} I M C$ and improved the growth of Co containing IMCs. Haseeb et al. (2017) provided an overview to discuss the effects of metallic nanoparticles on the characteristics of interfacial IMCs in Snbased solder joints on $\mathrm{Cu}$ substrates during reflow and thermal aging. The Ni, Co, Zn, Mo, Mn , and Ti nanoparticles were mechanically blended with the $S A C$ solder paste. It was shown that, through the paste mixing route, the $\mathrm{Ni}, \mathrm{Co}, \mathrm{Zn}$ and $\mathrm{Mn}$ nanoparticles greatly contributed to changing the morphology and reducing the thickness of the IMCs, which helped the solder joint to perform in a favourable way. Basak et al. (2018) investigated the addition of minor amounts of $\mathrm{Fe}$ or $\mathrm{Al}_{2} \mathrm{O}_{3}$ nanoparticles into $S A C$. Their results indicated that supplements of $\mathrm{Fe}$ nanoparticles formed $\mathrm{FeSn}$, together with the IMCs of $S A C$ alloy, i.e. $A g_{3} S n$ and $C u_{6} S n_{5}$, which stopped the growth of grains/IMCs during aging/reflowing. However, $\mathrm{Al}_{2} \mathrm{O}_{3}$ nanoparticles did not participate in phase formation but acted as a grain refiner. Yakymovych et al. (2017) added $N i$ nanoparticles into $S A C$ using a cold-pressing method in which powders of $S A C$ and $N i$ nanopowders were mixed mechanically, and processed into $8 \mathrm{~mm}$ diameter rods. It was observed that the presence of $\mathrm{Ni}$ nanoparticles in $S A C$ formed a $(\mathrm{Cu}, \mathrm{Ni})_{6} S n_{5}$ phase which participated in the refinement of the microstructure due to the fine distribution of IMCs in the $S n$ matrix. Gain and Zhang (2019) found that $0.5 \mathrm{Wt} \% \mathrm{Ni}$ nanoparticles in $S A C$ produced new $(\mathrm{Cu}, \mathrm{Ni})-\mathrm{Sn} I M C$ phases as shown in Figure 2. The new IMC phase refined the microstructure of $S A C$ and improved the mechanical reliability of electronic interconnections which, subsequently, enhanced the lifespan of miniaturised electronic products.

Carbon nanotubes (CNTS) have been acknowledged as offering better physical, electrical and mechanical properties, which make them suitable for the fabrication of novel composites (Nai et al., 2008). Zhu et al. (2018) worked on doping CNTs with three different ranges of diameters, 10-20, 40-60, and 60-100 nm, into $S A C$ (Figure 3). Their studies concluded that the addition of $C N T S$ into $S A C$ provided better performance. Among all, the addition of CNTs in $S A C$ in the range of diameter $(40-60 \mathrm{~nm})$ produced a refined microstructure by lowering the growth rate of the IMCs up to
30.9 per cent. The refinement in microstructure was attributed to the agglomeration and adsorption of CNTs in the solder matrix and IMCs interface.

Kumar et al. (2008) concluded that adding single-walled carbon nanotubes ( $S W C N T$ ) into $S A C$ played a significant role in reducing the average size of the IMCs due to the dispersion of nanotubes at the grain boundaries of the $\mathrm{Ag}_{3} \mathrm{Sn}$, which resulted in a uniform morphology. Xu et al. (2015) studied the impact of graphene-nano-sheets (GNSs) on $S A C$. Their study found that GNSs participated in restricting grain growth and gave fine IMCs. The average sizes of the IMCs, after addition of $0.03,0.07$, and $0.10 \mathrm{Wt} . \%$ GNSs reduced to $1.35,1.24$ and $1.21 \mu \mathrm{m}$, respectively, compared to $1.96 \mu \mathrm{m}$ for $S A C$. All these reduced size IMCs played a vital role in enhancing the solder joint reliability.

Overall, the addition of an appropriate composition of alloying elements, nanoparticles and composites can significantly change the microstructure of $S A C$ alloys. However, the addition of more than a critical composition can negatively impact the properties of the solder joints. Therefore, selecting the optimum doping concentrations is highly recommended.

\section{Mechanical properties}

Alloying elements and nanoparticles also play a significant role in improving the mechanical properties of $S A C$ alloys (Sun and Zhang, 2015). Table I shows the impact of adding alloying elements, nanoparticles or other materials on the mechanical properties of $S A C$.

Chuang et al. (2012) found that up to $1.0 \mathrm{Wt}$ \% of $T i$ in $S A C$ improved the mechanical properties. Their study also concluded that excess concentrations of $T i$ produced coarse $\mathrm{Ti}_{2} \mathrm{Sn}_{3}$ in the eutectic colonies which, subsequently, degraded the mechanical properties of SAC. Fallahi et al. (2012) determined that adding $0.2 \mathrm{Wt} . \%$ and $0.6 \mathrm{Wt} . \%$ of $F e$ increased the shear strength of $S A C$ up to $40 \mathrm{MPa}$ and $53 \mathrm{MPa}$, respectively. Zhang et al. (2012a) concluded that the addition of $0.8 \mathrm{Wt} . \%$ of $Z n$ increased the strength of the $S A C$. However, more than $0.8 \mathrm{Wt} . \%$ of $Z n$ gave disperse $C u-Z n I M C s$, which resulted in coarsening of the microstructure because of the

Figure 2 SEM images of (a) SAC and (b) SAC-0.5 Wt.\% nanosized Ni particles
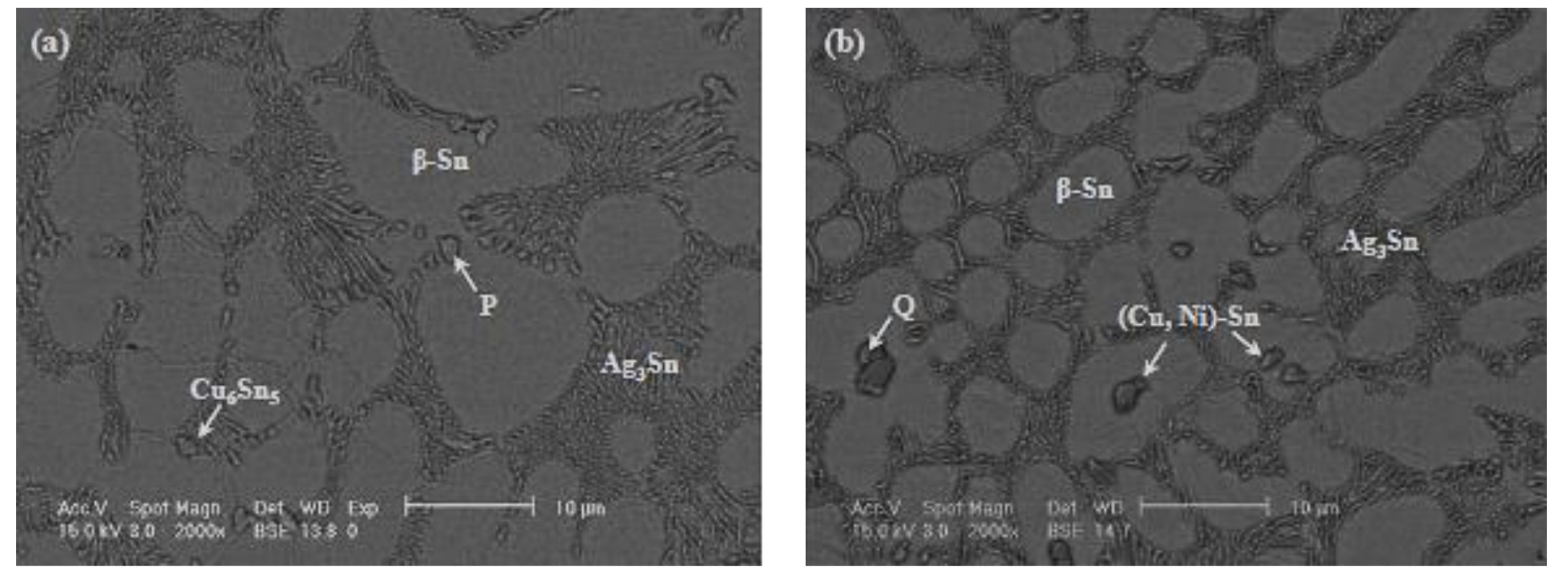

Source: Gain and Zhang (2019) 
Figure 3 (a) Schematic diagram of MWCNTs structure and TEM images of CNTs: (b) 10-20 nm, (c) 40-60 nm and (d) 60-100 nm
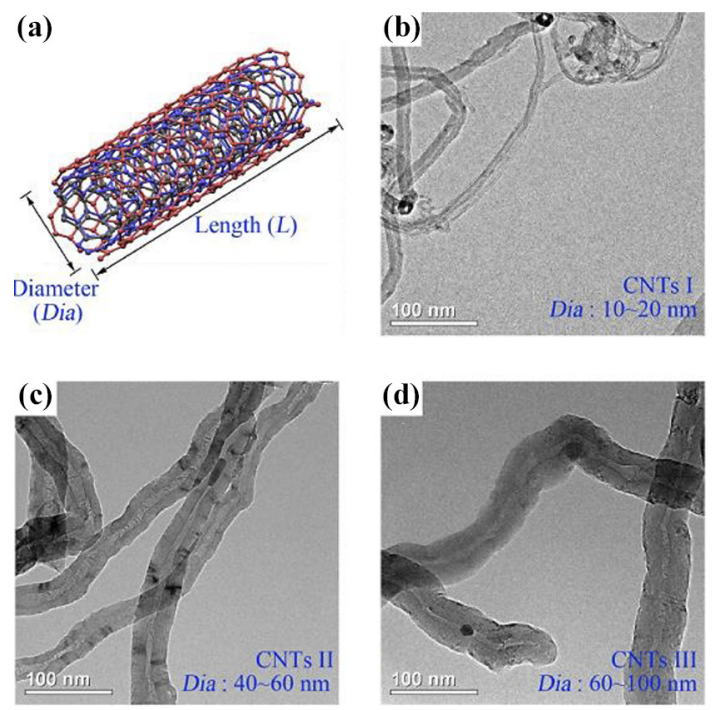

Source: Zhu et al. (2018)

great affinity of $Z n$ towards oxygen. Therefore, an excessive $Z n$ content resulted in the formation of $\mathrm{ZnO}_{2}$ which untimely reduced the tensile strength. El-Daly and El-Taher (2013) reported that $Y S, U T S$, and the ductility of $S A C$ were improved after the addition of $0.05 \mathrm{Wt} . \%$ of $\mathrm{Ni}$ because of the refined microstructure. However, addition of $0.1 \mathrm{Wt}$ \% of $N i$ into $S A C$ resulted in an abrasive microstructure which in turn degraded the mechanical properties. $\mathrm{Li}$ et al. (2006) and Chen and $\mathrm{Li}$ (2004) found, in their studies, that doping of $S b$ also improved the tensile strength of $S A C$. This improvement in strength was due to the reduced size of IMCs which ultimately refined the microstructure. The same investigation was detailed by Hammad (2018), who recommended adding $0.5 \mathrm{Wt} . \%$ of $S b$ into $S A C$ to improve the mechanical strength and ductility of the solder joint. In another study by Luo et al. (2014), the addition of up to $0.5 \mathrm{Wt}$. $\%$ of $G a$ was recommended to improve the shear strength of $S A C$ by 17.9 per cent.

Regarding $R E$ elements, Ali (2015) concluded that the optimum $L a$ concentration in $S A C$ for desired mechanical properties including YS, UTS and ductility was $0.3 \mathrm{Wt} \%$. Aamir et al. (2017b) reported that better mechanical properties could be obtained when the La composition was less than $0.4 \mathrm{Wt} . \%$, even after thermal ageing. Hao et al. (2007) found improvement in the strength of $S A C$ after the addition of $Y$; however, the joint strength decreased dramatically for $Y$ concentrations beyond $0.15 \mathrm{Wt} . \%$. Shi et al. (2008) reported that adding $\leq 0.1 \mathrm{Wt} . \% \mathrm{Er}$ to $S A C$ increased the shear strength significantly, due to the reduced size of $\mathrm{Ag}_{3} \mathrm{Sn}$ and $\mathrm{Cu}_{6} \mathrm{Sn}_{5}$. Gao et al. (2010a) concluded that, when the $N d$ supplement was $0.05 \mathrm{Wt} . \%$, the pull force and sheer force of the solder joint was improved by 19.4 per cent and 23.6 per cent, respectively. The improvement in pull force and sheer force was due to the refinement in the IMCs by $N d$. Their study also suggested that the amount of $N d$ in $S A C$ should not exceed $0.25 \mathrm{Wt} . \%$. In another study by Gao et al. (2010b), the addition of up to
$0.05 \mathrm{Wt} . \%$ of $\operatorname{Pr}$ also increased both the pull force and sheer force by 18.5 per cent and 19.4 per cent, respectively. Similarly, Zhang et al. (2014) reported that inclusions of $0.05 \mathrm{Wt} \% \mathrm{Yb}$ to the $S A C$ increased the tensile force of $S A C$ solder joints by 25.4 per cent. Tu et al. (2017) concluded that addition of $0.15 \mathrm{Wt} . \%$ of $C e$ into $S A C$ improved $E, Y S$ and UTS of $S A C$. Furthermore, $S A C-0.15 C e$ also gave better shear strength, even after thermal ageing, as shown in Figure 4.

Tsao et al. (2013) concluded that the addition of $1.0 \mathrm{Wt} . \%$ of $\mathrm{Al}_{2} \mathrm{O}_{3}$ nanoparticles increased the shear strength of $S A C$ after 1 and 8 reflow cycles by 14.4 per cent and 16.5 per cent, respectively. Tang et al. (2014) added different compositions of $\mathrm{TiO}_{2}$ nanoparticles into $S A C$ which improved the mechanical properties at the $0.1 \mathrm{Wt} \% \%$ level. The improvement was due to refinement of the microstructure after the reduced space between the $\mathrm{Ag}_{3} \mathrm{Sn}$ IMCs. Bashir et al. (2016) concluded that a 2.0 Wt.\% Co nanoparticle-doped flux improved the reliability of $S A C$ solder joints because their tensile strengths increased after $0 \mathrm{~h}$ as well as $192 \mathrm{~h}$ of $E M$ testing at $150^{\circ} \mathrm{C}$. Gain and Zhang (2018) reported that adding $1.0 \mathrm{Wt} \%$ of $\mathrm{TiO}_{2}$ nanoparticles into $S A C$, prepared by a mechanical mixing process, enhanced the creep and shear strength. It was also noted that the $C u_{6} S n_{5}$ and $C u_{3} S n$ phases were observed on the $\mathrm{Cu}$ substrate through interfacial structure characterisation, and a ternary $(\mathrm{Cu}, \mathrm{Ni})-\mathrm{Sn}$ phase had grown on an $\mathrm{Au} / \mathrm{N} i$-plated $\mathrm{Cu}$ pad of a Ball Grid Array. These IMCs started growing during thermal aging, however, $\mathrm{TiO}_{2}$ nanoparticles suppressed the growth of the IMCs and thus, the creep, shear strength and thermal shock resistance were improved. Gain and Zhang (2019) found that, in addition to the improvement in electrical properties, the elastic modulus, shear modulus, and microhardness were also improved by 8 per cent, 11.2 per cent, and 16.7 per cent, respectively, when the addition of $N i$-nanoparticles into $S A C$ was $0.5 \mathrm{Wt} . \%$. The reason for the overall good properties of the solder joints was the appearance of relatively fine IMCs dispersed in a $\beta-S n$ matrix and the fine microstructure. Roshanghias et al. (2012) recommended that the best combination of mechanical properties was achieved with $0.75 \mathrm{Wt} . \%$ of $\mathrm{CeO}_{2}$ nanoparticles int $S A C$. Nai et al. (2006) suggested that the addition of $3.0 \mathrm{Vol} . \%$ of titanium diboride $\left(\mathrm{TiB}_{2}\right)$ nanoparticles resulted in improved levels of $Y S$ and UTS by 26 per cent and 23 per cent, respectively. Yang et al. (2014) concluded that adding $0.05 \mathrm{Wt} . \% \mathrm{Ni}$-coated carbon nanotubes ( $N i$-CNTs) into $S A C$ significantly improved the tensile strength. The prime reason for its better tensile strength was that the CNTs obstructed the start of dislocation motion in the SAC. Kumar et al. (2008) concluded that $1.0 \mathrm{Wt} . \%$ of $S W C N T$ enhanced the UTS of SAC up to 50 per cent. Zhu et al. (2018) also found that the reinforcement of CNTs in $S A C$ improved E, YS, and UTS. The recommended range of the diameter of the CNTs was $40-60 \mathrm{~nm}$, which contributed to reducing the growth of IMCs and thus, provided superior mechanical properties. Furthermore, upon addition of $0.03 \mathrm{Wt} . \%$ of GNSs, the UTS of $S A C$ was improved by $\sim 10$ per cent, because of the refined microstructure due to the reduced average size of the IMCs (XD Liu et al., 2013). Overall, the use of alloying elements and nanoparticles significantly contributed to the refinement of microstructure and improved mechanical properties of $S A C$ series solders. However, it should be noted that 
Table I Role of the fourth element in the mechanical properties of SAC

\begin{tabular}{|c|c|c|c|}
\hline Alloying element & $\begin{array}{l}\text { Composition weight } \\
\text { percentage }\end{array}$ & Mechanical properties & References \\
\hline$\overline{T i}$ & Up to $1.0 \mathrm{Wt} . \%$ & Increase the YS, UTS, and microhardness of SAC & Chuang et al. (2012) \\
\hline $\mathrm{Fe}$ & $0.6 \mathrm{Wt} \%$ & Shear strength of $S A C$ increases up to $53 \mathrm{MPa}$ from $29 \mathrm{MPa}$ & Fallahi et al. (2012) \\
\hline$Z n$ & $0.8 \mathrm{Wt} \%$ & Improves the tensile force of $S A C$ joints by $10 \%$ & Zhang et al. (2012a) \\
\hline $\mathrm{Ni}$ & $0.5 \mathrm{Wt} \%$ & Improves $Y S$, UTS and ductility of $S A C$ & El-Daly and El-Taher (2013) \\
\hline$S b$ & $0.5 \mathrm{Wt} . \%$ & Gives higher strength and ductility & Hammad (2018) \\
\hline Ga & Up to $0.5 \mathrm{Wt} . \%$ & Improves the shear strength of $S A C$ solder joints up to $17.9 \%$ & Luo et al. (2014) \\
\hline La & $0.3 \mathrm{Wt} . \%$ & $\begin{array}{l}\text { Increases in YS, UTS and ductility are found which then } \\
\text { improve toughness, creep and fatigue resistance of the SAC }\end{array}$ & $\operatorname{Ali}(2015)$ \\
\hline$Y$ & $<0.15$ Wt. $\%$ & The strength of the $S A C$ joint is improved & Hao et al. (2007) \\
\hline Er & $\leq 0.1 \mathrm{Wt} . \%$ & Shear strength of $S A C$ solder is improved by $18 \%$ & Shi et al. (2008) \\
\hline$N d$ & $0.05 \mathrm{Wt} . \%$ & $\begin{array}{l}\text { Pull force and sheer force of } S A C \text { joint are increased by } \\
19.4 \% \text { and } 23.6 \% \text {, respectively }\end{array}$ & Gao et al. (2010a) \\
\hline $\operatorname{Pr}$ & $0.05 \mathrm{Wt} . \%$ & Improves pull force and sheer force of $S A C$ solder & Gao et al. (2010b) \\
\hline$Y b$ & Up to $0.05 \mathrm{Wt} \%$ & The tensile force of the $S A C$ solder joint increase by $25.4 \%$ & Zhang et al. (2014) \\
\hline $\mathrm{Ce}$ & $0.15 \mathrm{Wt} . \%$ & Increase the shear strength, ductility, E, YS, and UTS & Tu et al. (2017) \\
\hline Al Nanoparticles & $3.0 \mathrm{Wt} \%$ & Improves the shear strength of $S A C$ & Gain et al. (2010) \\
\hline $\mathrm{Al}_{2} \mathrm{O}_{3}$ Nanoparticles & $1.0 \mathrm{Wt} . \%$ & $\begin{array}{l}\text { The shear strength after } 1 \text { cycle and } 8 \text { cycles of reflow is } \\
\text { increased by } 14.4 \% \text { and } 16.5 \% \text {, respectively }\end{array}$ & Tsao et al. (2013) \\
\hline $\mathrm{TiO}_{2}$ Nanoparticles & $0.1 \mathrm{Wt} \%$ & Gives better microhardness and tensile properties & Tang et al. (2014) \\
\hline $\mathrm{CeO}_{2}$ Nanoparticles & $0.75 \mathrm{Wt} . \%$ & Improves $Y S$ and UTS of SAC & Roshanghias et al. (2012) \\
\hline $\mathrm{TiB}_{2}$ Nanoparticles & 3 Vol. \% & Increase YS and UTS by $26 \%$ and $23 \%$, respectively & Nai et al. (2006) \\
\hline Co- nanoparticles & $2 \mathrm{Wt} . \%$ & Increases the tensile strength of $S A C$ & Bashir et al. (2016) \\
\hline Ni-nanoparticles & $0.5 \mathrm{Wt} \%$ & $\begin{array}{l}\text { The elastic modulus, shear modulus and microhardness } \\
\text { increase by } 8.0 \%, 11.2 \% \text { and } 16.7 \% \text { in } S A C \text {, respectively. }\end{array}$ & Gain and Zhang (2019) \\
\hline Ni-CNTs & $0.05 \mathrm{Wt} . \%$ & Improves the tensile strength of $S A C$ solder slabs and joints & Yang et al. (2014) \\
\hline SWCNT & $1.0 \mathrm{Wt} \%$ & Increases the UTS of SAC up to $50 \%$ & Kumar et al. (2008) \\
\hline MWCNT & $10-60 \mathrm{~nm}$ & Improvements in $E, Y S$ and UTS of $S A C$ were found & Zhu et al. (2018) \\
\hline GNSS & $0.03 \mathrm{Wt} . \%$ & Increased the UTS of SAC solder by approximately $10 \%$ & Liu et al. (2013) \\
\hline
\end{tabular}

there was also an appropriate maximum concentration beyond which those properties degraded.

\section{Wettability}

Wettability testing is used to examine the wetting properties that include surface tension and wetting force (Sadiq, 2012). Traditional $\mathrm{Sn}-\mathrm{Pb}$ solder has better wettability due to the presence of $\mathrm{Pb}$ (Dharma et al., 2009; Wu et al., 2004). Thus, when changing from $S n-P b$ to $L F S$, wettability becomes an important concern. Furthermore, most of the LFS alloys have good mechanical properties when tested in bulk but their wetting, when soldered on boards, is not good for the reliability of solder joints. This means that wettability, or solderability, is necessary for characterising the solder alloys and becomes important when high solder joint reliability is required (Sadiq, 2012).

There are two well-known tests used to characterise the wettability of solder: the spread area test and the wetting balance test (Wu et al., 2004). In the spread area test, a solder disc is coated with flux, melted, and allowed to solidify on a substrate. When a bond is formed, the free energy is reduced and hence the solder changes its shape (Wu et al., 2004). This change in shape causes an increase in the contact area which shows the wetting behaviour of the solder. In some cases, the ratio of the as-bonded area to this new area (after soldering) is taken as the wettability of the solder (Wu et al., 2004). Wetting balance testing is another important technique for evaluating solder wettability. In this method, a coupon (for example $\mathrm{Cu}$ ) is dipped into the molten solder. The molten solder moves up the coupon because of the wetting force exerted on it. Different forces, due to buoyancy, come into action after partial dipping of the coupon into the solder bath, including the surface tension, which are quite high at the solder/flux interface. The resultant force is then the measurement of the meniscus and the wetting angle (Sadiq, 2012).

In investigations into improving the wettability of $S A C$, the addition of $R E$ elements was the most noticeable (Xiong and Zhang, 2019). The wetting properties of SAC and SAC-La at $250^{\circ} \mathrm{C}$ were investigated by Sadiq (2012). It was noticed that the surface tension of $S A C$ decreased due to $L a$ doping. The wetting force of $S A C$ was $5.7 \mathrm{mN}$, which increased up to $6.7 \mathrm{mN}$ for $S A C-0.25 \mathrm{La}$ as shown in Figure 5(a). However, when the $L a$ content increased to $0.5 \mathrm{Wt} . \%$, the wetting force showed a lower value than $S A C-0.25 \mathrm{La}$. Thus, the addition of $L a$ in $S A C$ beyond $0.25 \mathrm{Wt} . \%$ decreased the wetting force, ultimately affecting the wettability. Therefore, the optimum level of $L a$ in $S A C$ should be considered as $0.25 \mathrm{Wt}$. \%. In the same study, wetting or contact angle were found on the basis of the surface tensions. An appreciable decrease in contact angle was noted with $S A C-0.25 \mathrm{La}$ having a better (smaller) contact 
Figure 4 Mechanical properties of SAC with different levels of $C e$

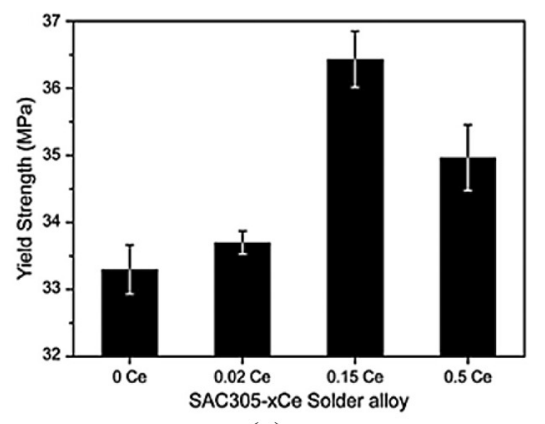

(a)

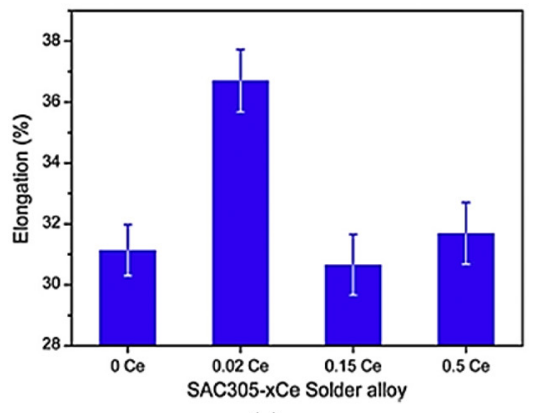

(c)

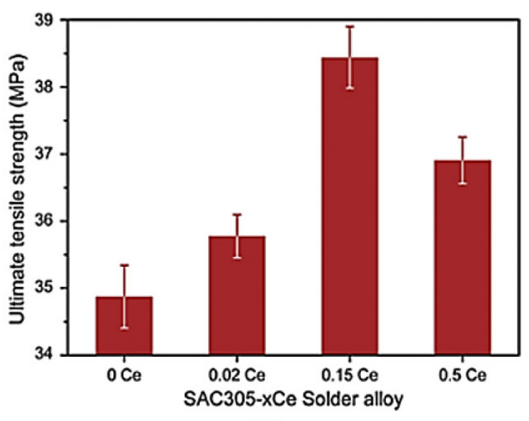

(b)

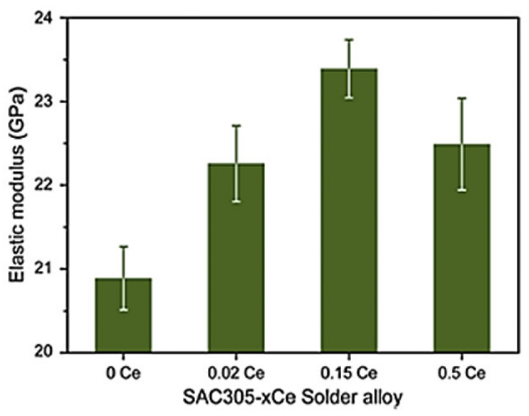

(d)

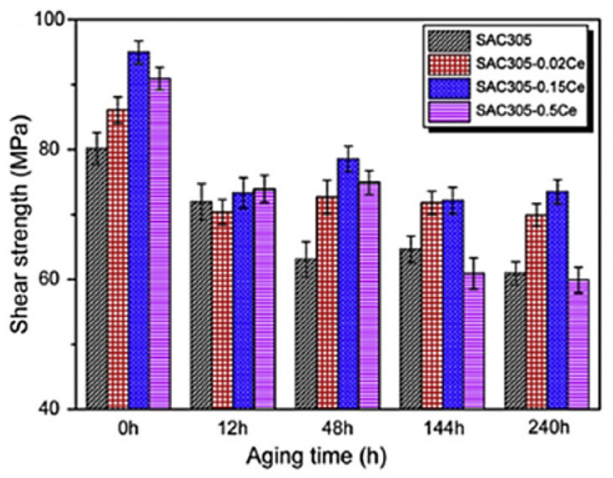

(e)

Source: Tu et al. (2017)

Figure $5 S A C$ and $S A C-L a$ at $250^{\circ} \mathrm{C}$

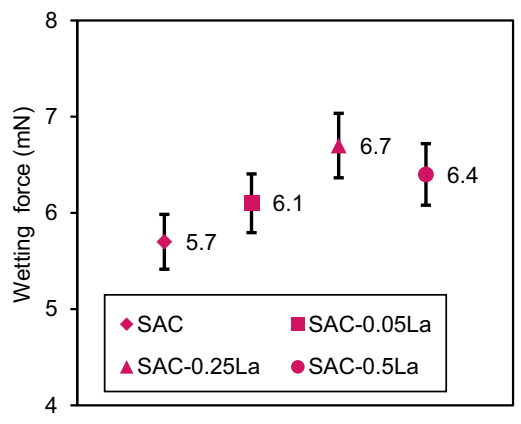

(a)

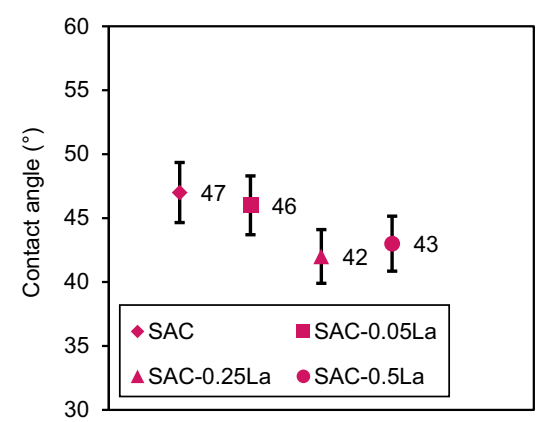

(b)

Notes: (a) Wetting forces; (b) contact angles Sadiq (2012) 
angle than $S A C$ and $S A C-0.5 L a$ alloys. Figure 5(b) shows that $S A C-0.25 L a$ decreased the wetting angle of $S A C$ from $47^{\circ}$ to $42^{\circ}$ and again $S A C-0.5 \mathrm{La}$ showed a larger wetting angle than $S A C-0.25 \mathrm{La}$. Therefore, the optimum doping of $\mathrm{La}$ in $S A C$ was $0.25 \mathrm{Wt} \%$, as beyond this the wetting angle increased, ultimately affecting the wettability.

Gao et al. (2010a) concluded that trace amounts of $N d$ remarkably improved the wetting behaviour of $S A C$. Figures 6(a) and (b) show the wetting time and wetting force of $S A C-N d$ at different temperatures, which clearly show that the wettability of $S A C$ improved with $0.05 \mathrm{Wt} \%$ of $\mathrm{Nd}$ because of its lower surface tension. Gao et al. (2010b) in another study also reported that $0.05 \mathrm{Wt} . \%$ of $\mathrm{Pr}$ improved the wetting properties of $S A C$. Figure 7 shows that the highest spreading area was $63.27 \mathrm{~mm}$, which was observed for $S A C-0.05 \mathrm{Pr}$.

Furthermore, the wettability of $S A C-C e$ was studied by Wang et al. (2009). They concluded that, after the addition of $C e$, the wetting behaviour of $S A C$ improved significantly. The observed wetting time was $\sim 0.7 s$ at $250^{\circ} \mathrm{C}$, which was very close to that of $\mathrm{Sn}-\mathrm{Pb}$ solder.

Nanoparticles can also improve the performance of $S A C$. Tay et al. (2013) concluded that adding $N i$ nanoparticles into $S A C$ increased the wetting angle from $19.3^{\circ}$ to $29.9^{\circ}$. Yoon et al. (2005) reported that $C o$ nanoparticles in $S A C$ increased the wetting angle, but decreased the spreading rate. Similar effects with $C o$ nanoparticles were reported by Haseeb and Leng (2011). Tsao et al. (2010) found that $0.5 \mathrm{Wt} . \%$ of $\mathrm{Al}_{2} \mathrm{O}_{3}$ nanoparticles had the same effect on the wetting behaviour of $S A C$, giving a minimum contact angle of $28.9^{\circ}$. Li et al. (2014) produced mechanically mixed $\mathrm{TiO}_{2}$ nanoparticles in $S A C$. Their study showed that adding $0.25 \mathrm{Wt} . \%$ of $\mathrm{TiO}_{2}$ nanoparticles decreased the wetting time by 53.7 per cent, while the wetting force increased to 37.6 per cent. Kanlayasiri and Meesathien (2018) reported that the maximum wettability of $S A C$ was achieved with $0.25 \mathrm{Wt} . \%$ of zinc oxide $(\mathrm{ZnO})$ nanoparticles. Jung et al. (2018) worked on different compositions of $\mathrm{TiO}_{2}$ and Graphene. All compositions were mixed simultaneously at equal weight fractions into $S A C$ molten solder by a mechanical mixing method and melting, to produce a bulk nanocomposite solder. Their results showed that a 0.21 Wt. $\%$ nanomaterial addition gave with had
Figure 7 Effect of Pr on the solderability of SAC

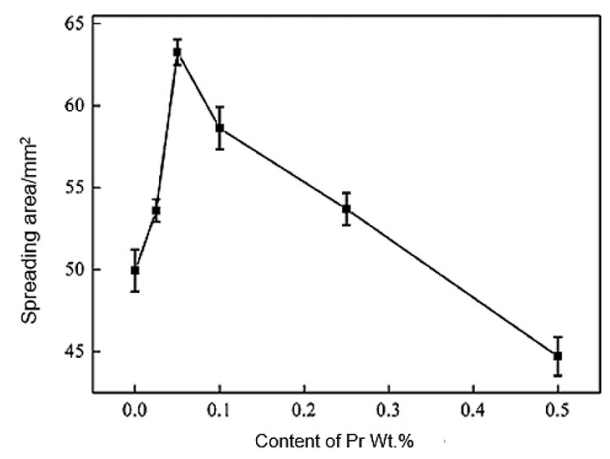

Source: Gao et al. (2010b)

wettability and spreadability improvements of 33.67 per cent and 8.66 per cent, respectively.

\section{Conclusions}

Lead-free solder alloys are considered to be one of the most important segments of the global green electronics environment. The most commonly used lead-free solder alloys are $S A C$ as they offer good mechanical properties comparison to conventional tin-lead. Addition of alloying elements or a composite approach can overcome limitations of these $S A C$ solders, especially the microstructure, mechanical properties, and wettability. However, no significant effect on the MP was observed and thus, no adjustment should be required in the reflow process to meet the requirement of the present soldering process. Further research is required to ensure that the addition of alloying elements or a composite approach can decrease the MP of tin-silver-copper. Moreover, it is worth noting that the addition of a fourth element or nanoparticles is actively involved in refining the microstructure, giving good mechanical properties and wettability, (with the condition that the added compositions should not be in an excess amount for the solder joint's reliability). In this regard, when developing new leadfree solder alloys, the optimum concentration of the material added to the tin-silver-copper should be carefully examined. Future studies should aim to determine the optimal additive

Figure 6 Effect of $N d$ on the solderability of SAC solders

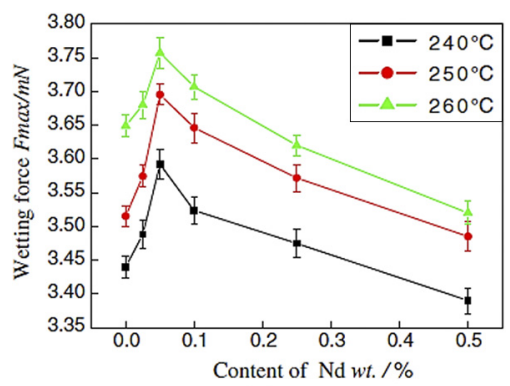

(a)

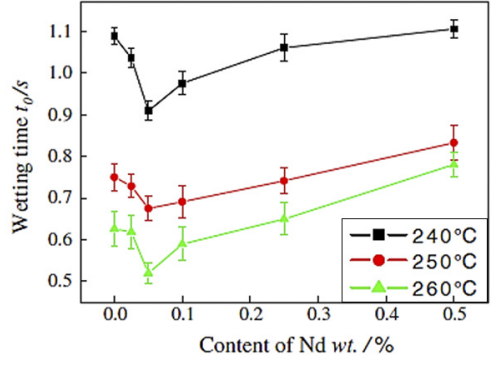

(b)

Notes: (a) Wetting force; (b) wetting time Source: Gao et al. (2010a) 
compositions that can improve the thermal behaviour, interfacial reactions, tin whiskering, wettability, microstructure and mechanical properties of SAC alloys. Moreover, the work should also be extended to find the desired inclusions into tinsilver-copper that can effectively exhibit better performance under different strain rates and, thermal ageing at different times and temperatures.

\section{References}

Aamir, M., Muhammad, R., Ahmed, N. and Alam, K. (2015), "Impact of thermal aging on microstructure and mechanical properties of high $\mathrm{Sn}$ content, $\mathrm{Sn}-\mathrm{Pb}$ solders", Fourth International Conference on Aerospace Science $\mathcal{E}$ Engineering, Islamabad, Pakistan, Institute of Space Technology, 2015, Islamabad, Pakistan, Institute of Space Technology, Islamabad, pp. 187-191.

Aamir, M., Muhammad, R., Ahmed, N. and Waqas, M. (2017b), "Impact of thermal aging on the intermetallic compound particle size and mechanical properties of lead free solder for green electronics", Microelectronics Reliability, Vol. 78, pp. 311-318.

Aamir, M., Muhammad, R., Ahmed, N., Sadiq, M. and Waqas, M. (2017a), "Mechanical properties of lead free solder alloy for green electronics under high strain rate and thermal aging", fournal of Engineering and Applied Sciences (fEAS), Vol. 36 No. 1, pp. 115-123.

Aamir, M., Waqas, M., Iqbal, M., Hanif, M.I. and Muhammad, R. (2017c), "Fuzzy logic approach for investigation of microstructure and mechanical properties of Sn96.5-Ag3.0-Cu0.5 lead free solder alloy”, Soldering $\mathcal{E}$ Surface Mount Technology, Vol. 29, pp. 191-198.

Aamir, M., Tolouei-Rad, M., Din, I.U., Giasin, K. and Vafadar, A. (2019), "Performance of SAC305 and SAC305$0.4 \mathrm{La}$ lead free electronic solders at high temperature", Soldering \& Surface Mount Technology, Vol. 31, pp. 250-260.

Abtew, M. and Selvaduray, G. (2000), "Lead-free solders in microelectronics", Materials Science and Engineering: R: Reports, Vol. 27 Nos 5/6, pp. 95-141.

Ali, B. (2015), "Advancement in microstructure and mechanical properties of lanthanum-doped tin-silvercopperlead free solders by optimizing the lanthanum doping concentration", Soldering \& Surface Mount Technology, Vol. 27, pp. 69-75.

Basak, A., Pramanik, A., Riazi, H., Silakhori, M. and Netting, A. (2018), "Development of Pb-free nanocomposite solder alloys", fournal of Composites Science, Vol. 2 No. 2, pp. 28.

Bashir, M.N., Haseeb, A., Rahman, A.Z.M.S. and Fazal, M. (2016), "Effect of cobalt doping on the microstructure and tensile properties of lead free solder joint subjected to electromigration", fournal of Materials Science \& Technology, Vol. 32, pp. 1129-1136.

Chang, S., Jain, C., Chuang, T., Feng, L. and Tsao, L. (2011), "Effect of addition of $\mathrm{TiO}_{2}$ nanoparticles on the microstructure, microhardness and interfacial reactions of Sn3.5AgXCu solder”, Materials \& Design, Vol. 32, pp. 4720-4727.

Che, F., Zhu, W., Poh, E.S., Zhang, X. and Zhang, X. (2010), "The study of mechanical properties of $\mathrm{Sn}-\mathrm{Ag}-\mathrm{Cu}$ lead-free solders with different $\mathrm{Ag}$ contents and $\mathrm{Ni}$ doping under different strain rates and temperatures", fournal of Alloys and Compounds, Vol. 507 No. 1, pp. 215-224.

Chen, B. and Li, G. (2004), "Influence of Sb on IMC growth in $\mathrm{Sn}-\mathrm{Ag}-\mathrm{Cu}-\mathrm{Sb} \mathrm{Pb}$-free solder joints in reflow process", Thin Solid Films, Vol. 462, pp. 395-401.

Chen, W., Kong, J. and Chen, W. (2011), "Effect of rare earth $\mathrm{Ce}$ on the microstructure, physical properties and thermal stability of a new lead-free solder", fournal of Mining and Metallurgy, Section B: Metallurgy, Vol. 47 No. 1, pp. 11-21.

Cheng, S., Huang, C.-M. and Pecht, M. (2017), "A review of lead-free solders for electronics applications", Microelectronics Reliability, Vol. 75, pp. 77-95.

Chuang, C., Tsao, L., Lin, H. and Feng, L. (2012), "Effects of small amount of active $\mathrm{Ti}$ element additions on microstructure and property of $\mathrm{Sn} 3.5 \mathrm{Ag} 0.5 \mathrm{Cu}$ solder", Materials Science and Engineering: A, Vol. 558, pp. 478-484.

Dharma, I.G.B.B., Shukor, M.H.A. and Ariga, T. (2009), "Wettability of low silver content lead-free solder alloy", Materials Transactions, Vol. 50 No. 5, pp. 1135-1138.

Dudek, M. and Chawla, N. (2010), "Effect of rare-earth (La, $\mathrm{Ce}$, and $\mathrm{Y}$ ) additions on the microstructure and mechanical behavior of Sn-3.9Ag-0.7Cu solder alloy", Metallurgical and Materials Transactions A, Vol. 41 No. 3, pp. 610-620.

Efzan Mhd Noor, E., Singh, A. and Tze Chuan, Y. (2013), “A review: influence of nano particles reinforced on solder alloy”, Soldering E Surface Mount Technology, Vol. 25, pp. 229-241.

Efzan, E. and Marini, A. (2012), "A review of solder evolution in electronic application", International fournal of Engineering, Vol. 1, pp. 2305-8269.

El-Daly, A. and El-Taher, A. (2013), "Improved strength of Ni and $\mathrm{Zn}$-doped $\mathrm{Sn}-2.0 \mathrm{Ag}-0.5 \mathrm{Cu}$ lead-free solder alloys under controlled processing parameters", Materials \& Design, Vol. 47, pp. 607-614.

El-Daly, A. and Hammad, A. (2012), "Enhancement of creep resistance and thermal behavior of eutectic $\mathrm{Sn}-\mathrm{Cu}$ lead-free solder alloy by Ag and in-additions", Materials $\mathcal{E}$ Design, Vol. 40, pp. 292-298.

El-Daly, A., Hammad, A., Fawzy, A. and Nasrallh, D. (2013), "Microstructure, mechanical properties, and deformation behavior of $\mathrm{Sn}-1.0 \mathrm{Ag}-0.5 \mathrm{Cu}$ solder after $\mathrm{Ni}$ and $\mathrm{Sb}$ additions", Materials E Design, Vol. 43, pp. 40-49.

Fallahi, H., Nurulakmal, M., Arezodar, A.F. and Abdullah, J. (2012), "Effect of iron and indium on IMC formation and mechanical properties of lead-free solder", Materials Science and Engineering: $A$, Vol. 553, pp. 22-31.

Gain, A.K. and Zhang, L. (2018), "The effects of $\mathrm{TiO}_{2}$ nanoparticles addition on the thermal shock resistance, shear strength and IMC layer growth of SAC305 alloy", Materialia, Vol. 3, pp. 64-73.

Gain, A.K. and Zhang, L. (2019), "Effects of Ni nanoparticles addition on the microstructure, electrical and mechanical properties of Sn-Ag-Cu alloy", Materialia, Vol. 5, p. 100234.

Gain, A.K., Chan, Y.C. and Yung, W.K. (2011), "Microstructure, thermal analysis and hardness of a $\mathrm{Sn}-\mathrm{Ag}-$ $\mathrm{Cu}-1 \mathrm{wt} \%$ nano- $\mathrm{TiO}_{2}$ composite solder on flexible ball grid array substrates", Microelectronics Reliability, Vol. 51 No. 5, pp. 975-984.

Gain, A.K., Fouzder, T., Chan, Y.C., Sharif, A., Wong, N.B. and Yung, W.K. (2010), "The influence of addition of Al 
nano-particles on the microstructure and shear strength of eutectic $\mathrm{Sn}-\mathrm{Ag}-\mathrm{Cu}$ solder on $\mathrm{Au} / \mathrm{Ni}$ metallized $\mathrm{Cu}$ pads", fournal of Alloys and Compounds, Vol. 506 No. 1, pp. 216-223.

Gao, L., Xue, S., Zhang, L., Sheng, Z., Zeng, G. and Ji, F. (2010a), "Effects of trace rare earth $\mathrm{Nd}$ addition on microstructure and properties of $\mathrm{SnAgCu}$ solder", fournal of Materials Science: Materials in Electronics, Vol. 21, pp. 643-648.

Gao, L., Xue, S., Zhang, L., Xiao, Z., Dai, W., Ji, F., Ye, H. and Zeng, G. (2010b), "Effect of praseodymium on the microstructure and properties of $\mathrm{Sn} 3.8 \mathrm{Ag} 0.7 \mathrm{Cu}$ solder", fournal of Materials Science: Materials in Electronics, Vol. 21, pp. 910-916.

Hammad, A. (2013), "Evolution of microstructure, thermal and creep properties of $\mathrm{Ni}$-doped $\mathrm{Sn}-0.5 \mathrm{Ag}-0.7 \mathrm{Cu}$ low-Ag solder alloys for electronic applications", Materials $\mathcal{E}$ Design (1980-2015), Vol. 52, pp. 663-670.

Hammad, A. (2018), "Enhancing the ductility and mechanical behavior of Sn-1.0Ag-0.5Cu lead-free solder by adding trace amount of elements $\mathrm{Ni}$ and Sb", Microelectronics Reliability, Vol. 87, pp. 133-141.

Hao, H., Tian, J., Shi, Y., Lei, Y. and Xia, Z. (2007), "Properties of $\mathrm{Sn} 3.8 \mathrm{Ag} 0.7 \mathrm{Cu}$ solder alloy with trace rare earth element Y additions", fournal of Electronic Materials, Vol. 36 No. 7, pp. 766-774.

Harrison, M., Vincent, J. and Steen, H. (2001), "Lead-free reflow soldering for electronics assembly", Soldering $\mathcal{E}$ Surface Mount Technology, Vol. 13, pp. 21-38.

Haseeb, A. and Leng, T.S. (2011), "Effects of Co nanoparticle addition to $\mathrm{Sn}-3.8 \mathrm{Ag}-0.7 \mathrm{Cu}$ solder on interfacial structure after reflow and ageing", Intermetallics, Vol. 19 No. 5, pp. 707-712.

Haseeb, A., Arafat, M., Tay, S. and Leong, Y. (2017), "Effects of metallic nanoparticles on interfacial intermetallic compounds in tin-based solders for microelectronic packaging", fournal of Electronic Materials, Vol. 46 No. 10, pp. 5503-5518.

Huang, M. and Wang, L. (2005), "Effects of Cu, Bi, and in on microstructure and tensile properties of $\mathrm{Sn}-\mathrm{Ag}-\mathrm{X}(\mathrm{Cu}, \mathrm{Bi}$, in $)$ solders", Metallurgical and Materials Transactions A, Vol. 36 No. 6, pp. 1439-1446.

Jeon, S-J., Hyun, S., Lee, H.-J., Kim, J.-W., Ha, S.-S., Yoon, J.-W., Jung, S.-B. and Lee, H.-J. (2008), "Mechanical reliability evaluation of $\mathrm{Sn}-37 \mathrm{~Pb}$ solder joint using high speed lap-shear test", Microelectronic Engineering, Vol. 85 No. 10, pp. 1967-1970.

Jung, D.-H., Sharma, A. and Jung, J.-P. (2018), "Influence of dual ceramic nanomaterials on the solderability and interfacial reactions between lead-free $\mathrm{Sn}-\mathrm{Ag}-\mathrm{Cu}$ and a $\mathrm{Cu}$ conductor", Fournal of Alloys and Compounds, Vol. 743, pp. 300-313.

Kanlayasiri, K. and Meesathien, N. (2018), "Effects of zinc oxide nanoparticles on properties of SAC0307 lead-free solder paste", Advances in Materials Science and Engineering, Vol. 2018, pp. 1-10.

Kanlayasiri, K., Mongkolwongrojn, M. and Ariga, T. (2009), "Influence of indium addition on characteristics of $\mathrm{Sn}$ $0.3 \mathrm{Ag}-0.7 \mathrm{Cu}$ solder alloy", fournal of Alloys and Compounds, Vol. 485 Nos 1/2, pp. 225-230.
Kumar, K.M., Kripesh, V. and Tay, A.A. (2008), "Single-wall carbon nanotube (SWCNT) functionalized $\mathrm{Sn}-\mathrm{Ag}-\mathrm{Cu}$ leadfree composite solders", Fournal of Alloys and Compounds, Vol. 450 Nos 1/2, pp. 229-237.

Lee, N.-C. (1997), "Getting ready for lead-free solders", Soldering E Surface Mount Technology, Vol. 9, pp. 65-69.

Leong, Y. and Haseeb, A. (2016), "Soldering characteristics and mechanical properties of $\mathrm{Sn}-1.0 \mathrm{Ag}-0.5 \mathrm{Cu}$ solder with minor aluminum addition", Materials, Vol. 9 No. 7, p. 522.

Li, G., Chen, B., Shi, X., Wong, S.C. and Wang, Z. (2006), "Effects of $\mathrm{Sb}$ addition on tensile strength of $\mathrm{Sn}-3.5 \mathrm{Ag}-$ 0.7Cu solder alloy and joint", Thin Solid Films, Vol. 504 Nos 1/2, pp. 421-425.

Li, Y., Zhao, X., Liu, Y., Wang, Y. and Wang, Y. (2014), "Effect of $\mathrm{TiO}_{2}$ addition concentration on the wettability and intermetallic compounds growth of $\mathrm{Sn} 3.0 \mathrm{Ag} 0.5 \mathrm{Cu}-\mathrm{xTiO}_{2}$ nano-composite solders", Fournal of Materials Science: Materials in Electronics, Vol. 25, pp. 3816-3827.

Liang, J., Luo, T., Hu, A. and Li, M. (2014), "Formation and growth of interfacial intermetallic layers of $\mathrm{Sn}-8 \mathrm{Zn}-3 \mathrm{Bi}-$ $0.3 \mathrm{Cr}$ on $\mathrm{Cu}, \mathrm{Ni}$ and $\mathrm{Ni}-\mathrm{W}$ substrates", Microelectronics Reliability, Vol. 54 No. 1, pp. 245-251.

Liu, P., Yao, P. and Liu, J. (2008), "Effect of SiC nanoparticle additions on microstructure and microhardness of $\mathrm{Sn}-\mathrm{Ag}-\mathrm{Cu}$ solder alloy", fournal of Electronic Materials, Vol. 37 No. 6, pp. 874-879.

Liu, X., Han, Y., Jing, H., Wei, J. and Xu, L. (2013), "Effect of graphene nanosheets reinforcement on the performance of $\mathrm{SnAgCu}$ lead-free solder", Materials Science and Engineering: $A$, Vol. 562, pp. 25-32.

Luo, D-X., Xue, S-B. and Li, Z-Q. (2014), "Effects of Ga addition on microstructure and properties of $\mathrm{Sn}-0.5 \mathrm{Ag}-0.7$ $\mathrm{Cu}$ solder", Fournal of Materials Science: Materials in Electronics, Vol. 25, pp. 3566-3571.

Ma, H. and Suhling, J.C. (2009), "A review of mechanical properties of lead-free solders for electronic packaging", Fournal of Materials Science, Vol. 44 No. 5, pp. 1141-1158.

Mei, Z., Holder, H.A. and Vander Plas, H.A. (1996), "Lowtemperature solders", Hewlett Packard Fournal, Vol. 47, pp. 91-98.

Nai, S., Wei, J. and Gupta, M. (2006), "Influence of ceramic reinforcements on the wettability and mechanical properties of novel lead-free solder composites", Thin Solid Films, Vol. 504 Nos 1/2, pp. 401-404.

Nai, S., Wei, J. and Gupta, M. (2008), "Effect of carbon nanotubes on the shear strength and electrical resistivity of a lead-free solder", Fournal of Electronic Materials, Vol. 37 No. 4, pp. 515-522.

Nimmo, K. (2004), "Alloy selections", Lead-Free Soldering in Electronics - Science, Technology and Environmental Impact, pp. 49-90.

Roshanghias, A., Kokabi, A., Miyashita, Y., Mutoh, Y., Rezayat, M. and Madaah-Hosseini, H. (2012), "Ceria reinforced nanocomposite solder foils fabricated by accumulative roll bonding process", fournal of Materials Science: Materials in Electronics, Vol. 23, pp. 1698-1704.

Sabri, M.F.M., Shnawah, D.A., Badruddin, I.A., Said, S.B. M., Che, F.X. and Ariga, T. (2013), "Microstructural stability of $\mathrm{Sn}-1 \mathrm{Ag}-0.5 \mathrm{Cu}-\mathrm{xAl}(\mathrm{x}=1,1.5$, and $2 \mathrm{wt} . \%)$ solder alloys and the effects of high-temperature aging on 
their mechanical properties", Materials Characterization, Vol. 78, pp. 129-143.

Sadiq, M. (2012), "Design and fabrication of lanthanumdoped $\mathrm{Sn}-\mathrm{Ag}-\mathrm{Cu}$ lead-free solder for next generation microelectronics applications in severe environment", Doctoral dissertation, Georgia Institute of Technology.

Sadiq, M., Pesci, R. and Cherkaoui, M. (2013), "Impact of thermal aging on the microstructure evolution and mechanical properties of lanthanum-doped tin-silvercopperlead-free solders", Fournal of Electronic Materials, Vol. 42 No. 3, pp. 492-501.

Sharma, A., Yu, H., Cho, I.S., Seo, H. and Ahn, B. (2019), " $\mathrm{ZrO}_{2}$ nanoparticle embedded low silver lead free solder alloy for modern electronic devices", Electronic Materials Letters, Vol. 15 No. 1, pp. 27-35.

Shi, Y., Tian, J., Hao, H., Xia, Z., Lei, Y. and Guo, F. (2008), "Effects of small amount addition of rare earth $\mathrm{Er}$ on microstructure and property of $\mathrm{SnAgCu}$ solder", fournal of Alloys and Compounds, Vol. 453 Nos 1/2, pp. 180-184.

Shnawah, D.A., Sabri, M.F.M. and Badruddin, I.A. (2012), "A review on thermal cycling and drop impact reliability of SAC solder joint in portable electronic products", Microelectronics Reliability, Vol. 52 No. 1, pp. 90-99.

Shnawah, D.A., Sabri, M.F.M., Badruddin, I.A., Said, S.B. M., Ariga, T. and Che, F.X. (2013), "Effect of Ag content and the minor alloying element $\mathrm{Fe}$ on the mechanical properties and microstructural stability of Sn-Ag-Cu solder alloy under high-temperature annealing", Fournal of Electronic Materials, Vol. 42 No. 3, pp. 470-484.

Sona, M. and Prabhu, K. (2013), "Review on microstructure evolution in $\mathrm{Sn}-\mathrm{Ag}-\mathrm{Cu}$ solders and its effect on mechanical integrity of solder joints", Fournal of Materials Science: Materials in Electronics, Vol. 24, pp. 3149-3169.

Sujan, G., Haseeb, A., Nishikawa, H. and Amalina, M. (2017), "Interfacial reaction, ball shear strength and fracture surface analysis of lead-free solder joints prepared using cobalt nanoparticle doped flux", Fournal of Alloys and Compounds, Vol. 695, pp. 981-990.

Sun, L. and Zhang, L. (2015), "Properties and microstructures of Sn-Ag-Cu-X lead-free solder joints in electronic packaging", Advances in Materials Science and Engineering, Vol. 2015, p. 16.

Tang, Y., Li, G. and Pan, Y. (2014), "Effects of $\mathrm{TiO}_{2}$ nanoparticles addition on microstructure, microhardness and tensile properties of $\mathrm{Sn}-3.0 \mathrm{Ag}-0.5 \mathrm{Cu}-\mathrm{xTiO}_{2}$ composite solder”, Materials E Design, Vol. 55, pp. 574-582.

Tay, S., Haseeb, A., Johan, M.R., Munroe, P. and Quadir, M. Z. (2013), "Influence of Ni nanoparticle on the morphology and growth of interfacial intermetallic compounds between $\mathrm{Sn}-3.8 \mathrm{Ag}-0.7 \mathrm{Cu}$ lead-free solder and copper substrate", Intermetallics, Vol. 33, pp. 8-15.

Tsao, L., Chang, S., Lee, C., Sun, W. and Huang, C. (2010), "Effects of nano- $\mathrm{Al}_{2} \mathrm{O}_{3}$ additions on microstructure development and hardness of $\mathrm{Sn} 3.5 \mathrm{Ag} 0.5 \mathrm{Cu}$ solder", Materials $\mathcal{E}$ Design, Vol. 31, pp. 4831-4835.

Tsao, L., Wu, R., Cheng, T.-H., Fan, K.-H. and Chen, R. (2013), "Effects of nano- $\mathrm{Al}_{2} \mathrm{O}_{3}$ particles on microstructure and mechanical properties of $\mathrm{Sn} 3.5 \mathrm{Ag} 0.5 \mathrm{Cu}$ composite solder ball grid array joints on $\mathrm{Sn} / \mathrm{Cu}$ pads”, Materials $\mathcal{E}$ Design, Vol. 50, pp. 774-781.
Tu, X., Yi, D., Wu, J. and Wang, B. (2017), "Influence of Ce addition on $\mathrm{Sn}-3.0 \mathrm{Ag}-0.5 \mathrm{Cu}$ solder joints: thermal behavior, microstructure and mechanical properties", fournal of Alloys and Compounds, Vol. 698, pp. 317-328.

Vianco, P. and Shangguan, D. (2006), Fatigue and Creep of Lead-Free Solder Alloys: fundamental Properties, Chapter 3, Leadfree Solder Interconnect Reliability, ASM International, Materials Park, OH, pp. 67-106.

Wang, H., Lu, T., Yi, D. and Wang, B. (2019), "Microstructure refinement, characterization of tensile behavior and aging resistance of $\mathrm{Zr}$-modified SAC105 solder alloy", fournal of Materials Science: Materials in Electronics, Vol. 30, pp. 11429-11439.

Wang, J.-X., Xue, S.-B., Han, Z.-J., Yu, S.-L., Chen, Y., Shi, Y.-P. and Wang, H. (2009), "Effects of rare earth Ce on microstructures, solderability of $\mathrm{Sn}-\mathrm{Ag}-\mathrm{Cu}$ and $\mathrm{Sn}-\mathrm{Cu}-\mathrm{Ni}$ solders as well as mechanical properties of soldered joints", fournal of Alloys and Compounds, Vol. 467 Nos 1/2, pp. 219-226.

Wu, C. and Wong, Y. (2007), "Rare-earth additions to leadfree electronic solders", Fournal of Materials Science: Materials in Electronics, Vol. 18, pp. 77-91.

Wu, C., Yu, D., Law, C. and Wang, L. (2004), "Properties of lead-free solder alloys with rare earth element additions", Materials Science and Engineering: R: Reports, Vol. 44 No. 1, pp. 1-44.

Xia, Z., Chen, Z., Shi, Y., Mu, N. and Sun, N. (2002), "Effect of rare earth element additions on the microstructure and mechanical properties of tin-silver-bismuth solder", fournal of Electronic Materials, Vol. 31 No. 6, pp. 564-567.

Xiong, M-y. and Zhang, L. (2019), "Interface reaction and intermetallic compound growth behavior of Sn-Ag-Cu leadfree solder joints on different substrates in electronic packaging", fournal of Materials Science, Vol. 54 No. 2, pp. 1741-1768.

Xu, L., Wang, L., Jing, H., Liu, X., Wei, J. and Han, Y. (2015), "Effects of graphene nanosheets on interfacial reaction of $\mathrm{Sn}-\mathrm{Ag}-\mathrm{Cu}$ solder joints", fournal of Alloys and Compounds, Vol. 650, pp. 475-481.

Yakymovych, A., Plevachuk, Y., Sklyarchuk, V., Sokoliuk, B., Galya, T. and Ipser, H. (2017), "Microstructure and electro-physical properties of $\mathrm{Sn}-3.0 \mathrm{Ag}-0.5 \mathrm{Cu}$ nanocomposite solder reinforced with $\mathrm{Ni}$ nanoparticles in the melting-solidification temperature range", fournal of Phase Equilibria and Diffusion, Vol. 38 No. 3, pp. 217-222.

Yang, Z., Zhou, W. and Wu, P. (2014), "Effects of Ni-coated carbon nanotubes addition on the microstructure and mechanical properties of $\mathrm{Sn}-\mathrm{Ag}-\mathrm{Cu}$ solder alloys", Materials Science and Engineering: A, Vol. 590, pp. 295-300.

Yasmin, T. and Sadiq, M. (2014), "Impact of lanthanum doping on SAC305 lead free solders for high temperature applications", Fournal of Engineering and Applied Sciences (FEAS), Vol. 33 No. 1, pp. 29-36.

Yoon, J.-W., Kim, S.-W. and Jung, S.-B. (2005), "IMC morphology, interfacial reaction and joint reliability of $\mathrm{Pb}-$ free $\mathrm{Sn}-\mathrm{Ag}-\mathrm{Cu}$ solder on electrolytic Ni BGA substrate", fournal of Alloys and Compounds, Vol. 392 Nos 1/2, pp. 247-252. 
Zhang, L., Fan, X-y., Guo, Y-h. and He, C-W. (2014), "Properties enhancement of $\mathrm{SnAgCu}$ solders containing rare earth Yb", Materials $\mathcal{E}$ Design, Vol. 57, pp. 646-651.

Zhang, L., Han, J-G., He, C-W. and Guo, Y-h. (2012a), "Effect of $\mathrm{Zn}$ on properties and microstructure of $\mathrm{SnAgCu}$ alloy", fournal of Materials Science: Materials in Electronics, Vol. 23, pp. 1950-1956.

Zhang, L., Xue, S.B., Zeng, G., Gao, L.L. and Ye, H. (2012b), "Interface reaction between $\mathrm{SnAgCu} / \mathrm{SnAgCuCe}$ solders and $\mathrm{Cu}$ substrate subjected to thermal cycling and isothermal aging", Fournal of Alloys and Compounds, Vol. 510 No. 1, pp. 38-45.

Zhu, Z., Chan, Y.-C., Chen, Z., Gan, C.-L. and Wu, F. (2018), "Effect of the size of carbon nanotubes (CNTs) on the microstructure and mechanical strength of CNTs-doped composite Sn0.3Ag0.7Cu-CNTs solder", Materials Science and Engineering: $A$, Vol. 727, pp. 160-169.

\section{Corresponding author}

Muhammad Aamir can be contacted at: m.aamir@ecu.edu.au 